\title{
Conflict Competence: An Exploration of its importance and skills
}

\author{
Vedabhyas Kundu \\ Programme Officer, Gandhi Smriti and Darshan Samiti, New Delhi, India \\ Corresponding author: vedabhyas@gmail.com
}

Received: 16 Feb., 2020

Revised: 19 May, 2020

Accepted: 04 June, 2020

\begin{abstract}
In a world where individuals have to negotiate a variety of conflicts in their daily lives- right from the individual level to societal level, it is critical that we strive to develop our conflict competencies. Enhancing our conflict competencies will help us negotiate the complexities in different conflict situations that we may encounter. Nurturing appropriate skills and abilities to analyze the root causes of conflicts and developing capabilities to address these will help us to ensure lasting resolution of these conflicts. Developing conflict competencies is not a one-time training process; instead it is an ongoing process requiring constant additions to skills and experiences. This chapter will explore the different dimensions of conflict competencies, its role and importance in contemporary society.
\end{abstract}

Keywords: Conflict competence, conflict resolution, conflict, constructive engagement

In your veins, and in mine, there is only one blood, the same life that animates us all. Since one unique mother begot us all, where did we learn to divide ourselves.

- Saint Kabir

Conflicts are part and parcel of human nature. Whether at individual level, family level, institution level or at the level of societies, conflicts have coexisted ever since the advent of human beings. It happens when differences between human beings becomes an issue. In modern societies it is impossible for individuals or groups to avoid situations of different types of conflict in the course of their lives. Right from childhood, in our schools, in other institutions, in work places and in our married lives, we encounter different types of conflicts. All these conflicts are also a great learning opportunities for the next conflict that we might encounter again. Much of the conflicts emanate from miscommunication, stereotypes, cultural disconnects, ego, misunderstandings and overall lack of adequate respect for the other person.
Most of the times differences do not result in anything serious. Many of the conflicts can be easily resolved, some may be avoidable if handled promptly. But if handled badly, even small differences can explode into big conflicts. The ingenuity of how to handle the differences by those who have become adversaries determines on how it is resolved. It is in this context that conflict competence becomes important. In simple terms, it is the ability of those in conflict to address the root cause of their differences and handle these constructively.

How to cite this article: Kundu, V. (2020). Conflict Competence: An Exploration of its importance and skills. Int. J. Peace, Edu. and Deve., 8(01): 01-05.

Source of Support: None; Conflict of Interest: None 
In the backdrop of increasing competing indulgences and the race for crass materialism, we find conflicts in our societies are becoming more complex. With individuals and groups trying to outwit each other due to increasingly scarce resources and the competition to succeed at any cost, many of these conflicts leads to complete breakdown of relationship and can even result in violence. A selfcentered attitude is one of the main root cause of conflicts in our societies.

\section{Objective \& Approach}

The challenge hence is to constantly enhance one's conflict competence to be able to constructively handle differences and conflicts we may encounter in our lives. The challenge is also to build groups and communities which conflict competent. This research will explore the different dimensions of conflict competence and try to locate its criticality in contemporary society.

The approach to this research is incremental based on wisdom of spiritual and social thinkers, as well as some prominent empirical studies. It is a construction in progress. At this moment, its limitation being incorporating wisdoms from few of the thinkers the choice of whom stemmed from 'who are in common parlance and media mentions'.

\section{Developing Conflict Competence in Modern Societies}

Runde and Flanagan (2010) points out, "Conflict competence is the ability to develop and use cognitive, emotional, and behavioral skills that enhance productive outcomes of conflict while reducing the likelihood of escalation or harm. The results of conflict competence include improved quality of relationships, creative solutions, and lasting agreements for addressing challenges and opportunities in the future."

According to Runde and Flanagan developing skills, learning mental models, and applying basic principles are the keys to developing conflict competence. They observe, "Those who deal well with emotions, are mindful of the ramifications of conflict, and use effective skills during conflict have the best chance of productive outcomes."

Developing conflict competence would mean how it would help individuals and groups to dissect beneath the surface the hidden meanings and likely causes of the conflict. There could be an underplay of wide ranging phenomenon which are triggers for a conflict - these include fears, desires, interests, cultural issues, economic issues, emotions, inequalities, historical issues and intentions. A conflict competent individual or groups have the capabilities to understand and analyze these from a broad perspective. This in turn becomes an important source of resolution of the conflict.

An important foundational architecture of enhancing conflict competence could be Mahatma Gandhi's five pillars of nonviolence. Gandhi (2017) talks about the five pillars of Mahatma Gandhi's nonviolence which includes: respect, understanding, acceptance, appreciation and compassion.

In many cases, differences arise because of lack of mutual respect. This can be due to multiple reasons- ego, cultural disconnect and stereotypes. The inherent lack of mutual respect can lead to misunderstandings as it is generally observed that it is much easier to connect and understand each other when there is mutual respect. Also when there is enough understanding, it is much easier to accept each other's position. Conflicts can accentuate if the adversaries are not ready to accept each other's position, are inflexible and don't show openness. In this context, the three pillars- respect, understanding and acceptance are all interconnected.

The fourth pillar of Gandhian nonviolence is appreciation. Much of the conflicts that we may encounter arise due to our own negative thoughts and emotions. As we try to negotiate the complexities of modern societies, many of us get entrapped in negative energies. Even slightest lack of success leads us to believe that nothing good is happening around us. The challenge hence is to nurture the habit of positive appreciation. When we start identifying the positive things around us, we are likely to nurture positive energy and positive emotions. The element of positivity can help us to handle conflicts creatively and constructively. 
Compassion is the fifth pillar of Gandhian nonviolence. As a skill, compassion needs to be constantly cultivated. Compassion helps us to recognize our shared humanity. Jinpa (2015) gives an in-depth understanding of compassion, "Compassion is a sense of concern that arise when we are confronted with another's suffering and feel motivated to see that suffering is relieved. Compassion is what connects the feelings of empathy to acts of kindness, generosity and other expressions of altruistic tendencies."

His Holiness The Dalai Lama has been more than often underlining the essence of compassion. He (2016) notes, "The concern for others is very precious. We humans have a special brain, but this brain causes a lot of suffering because it is always thinking me, me, me. The more time you spend thinking about yourself, the more suffering you will experience. The incredible thing is that when we think of alleviating other people's suffering, our own suffering is reduced."

In fact, as His Holiness The Dalai Lama argues on how suffering is caused by incessant thinking of only oneself, it is actually the cause of most of the conflicts that we encounter. Extreme selfishness plugs our vision to see other people's perspectives and this can be the underlying cause of differences. Hence nurturing skills of compassion is critical for enhancing our conflict competence.

For enhancing one's conflict competence development of cognitive skills is important. It will help in analyzing the conflict and its impact. Here it can be pointed out that cognitive differences between adversaries can be said to be primary cause of conflict. Also individual cognitive skills in making judgements and understanding each other's position plays an important role in how the conflict can be resolved. For instance, Kahneman and Taversky (2004) talking on the cognitive perspective talks of three phenomena which could hinder resolution of conflicts. These include optimistic overconfidence, the certainty effect and loss aversion.

Meanwhile Runde and Flanagan (2010) describes on why cognitive skills should include 'developing one's self-awareness about one's current attitudes and responses to conflict and an understanding of conflict's basic dynamics'. Developing one's self awareness is critical as it can shape how an individual would be able to deal with a conflict situation. If we are not aware that our mind could be full of wound and emotional poison, we will not be able to clean and heal the wounds. Expansive understanding of the self and self-awareness can play an important role on how an individual analyzes a particular conflict and the triggers which would determine on how s/he might respond. Here it would be useful to underline that adversaries mostly comes to the table for resolution of conflict with a negative perception. The challenge is to change the negative perception to positive perception. It is in this case that self-aware individuals can play a more positive resolution.

At the basic level, it can be said that conflicts arise due to emotions. While emotions play an important role in triggering conflicts, constructive handling of emotions offers a pathway to resolving these conflicts. Hence development of emotional skills is an important part of conflict competence. Runde and Flanagan observes, "Emotional skills include understanding one's emotional responses to conflict, regulating those responses to attain and maintain emotional balance, understanding and responding to the emotions of one' s conflict partners, and when necessary slowing down to allow extra time to cool down."

As it can be pointed out that our negative thoughts and emotions are sites of triggering conflicts, it is important to see how we can practice positive thoughts and emotions. The importance of positive appreciation was discussed in the five-pillars of Gandhian nonviolence. Negative thoughts and emotions will not let individuals look at other person's perspective constructively. Even if the issue is trivial, the negativities can actually lead it to become a full-blown conflict. Also negativities make individuals narrow-minded which is again a bottleneck in the way of resolution of conflicts.

On the other hand, when individuals practice positive emotions it helps in countering the negative emotions and thoughts. It also helps in widening 
of perspectives. Positive energies aid people to reflect positively. It helps in connecting come out with positive meaning and appraisals of even conflict situations. In fact, an important aspect of conflict transformation is how we use the conflict situation as an opportunity to learn and strengthen relationships.

Positive thoughts and emotions entails that the conflict is not seen as a threat; instead it is viewed as an opportunity to grow and increase an understanding of one's self and others. It helps navigating a destructive process of conflict to a constructive process.

It is in this backdrop, developing emotional intelligence can be an important requirement of being conflict competent. An emotional intelligent person will have the necessary skills to deeply understand one's own emotion and be able to recognize the emotions in others. As it has been mentioned that constructive resolution of conflict entails reframing the negative perception to a positive perception, an individual or group involved in the process of conflict resolution with adequate emotional intelligence will be able to discern the emotions underplay amongst all parties. This will aid to reframe the perception to a positive one. Another important aspect of emotional intelligence is the ability to practice self-restraint in expression of one's emotions and be able to constantly monitor it. Again this is critical as in situation of heightened arguments in a conflict, if neither parties do not self-regulate their emotional outbursts, it would trigger even bigger conflict. Hence, self-restraint of one's emotions can play a calming effect and will help in slowing down the aggressive postures by the adversaries. Also emotional intelligence helps individuals to motivate oneself and others; this can be a tool to weave positive energy in the process of conflict resolution.

For developing conflict competence, development of one's behavioral skills is also important. Runde and Flanagan (2010) points out, "Behavioral skills include engaging constructively by understanding others' perspectives, emotions, and needs; sharing one's own thoughts, feelings, and interests; collaborating to develop creative solutions to issues; and reaching out to get communications restarted when they have stalled."

Here it would be pertinent to analyze on what kind of behavioral skills are essential for constructive resolution of conflicts. Developing greater understanding of different perspectives are crucial in the conflict resolution process; this necessitates skills of deep listening. Deep listening can help transform an individual's attitude towards themselves and others. In fact, the art and science of listening in inherently linked to the fundamental ability to connect with one another.

Another important behavior skill essential for development conflict competence is the capacity to work collaboratively. Constructive resolution of conflicts which leads to a win-win situation underlines the importance of collaboration. All parties involved in the conflict need to effective collaborate to search for the most acceptable solution to the problem. The platform of conflict resolution should be a 'safe space' where each party can safely express their views and will feel motivated to work collaboratively with others to ensure a win-win resolution of the conflict.

An important aspect of conflict competence is development of skills in nonviolent communication. If the communication between the adversaries continue to be aggressive in nature, then there are possibilities of breakdown in communication, where none of the parties will be motivated to talk to each other. This is not a conducive environment for constructive conflict resolution. In fact, communication is the key in the process of conflict resolution. Use of strategies of nonviolent communication would help in plugging the trust deficit. As it advocates flexible and openness in communication, the channels of communication will not get blocked and the conflicting parties will still find meaning in continuing their interactions. Ensuring that the communication process continues in some form or the other is crucial in the search of acceptable solutions in a conflict.

The essence, hence, is to learn on how to engage with adversaries constructively. This is an integral 
part of conflict competence. In this context, Runde and Flanagan points out, "Engaging constructively also involves reducing or eliminating the use of destructive behaviors characterized by fight - or flight responses to conflict."

\section{CONCLUSION}

This article tried to explore the importance of conflict competence in modern societies - both at the individual level and community level. It tried to argue on why conflict competent communities need to be promoted so as to handle complex conflicts in contemporary times. The chapter also explored the different sets of skills one need to acquire to be conflict competent. It looked at cognitive skills, emotional skills and behavioral skills which are integral part of conflict competence. As discussed, developing one's conflict competence is an organic process and individuals need to continuously strive to acquire these skills so that they can contribute toward a culture of peace and nonviolence.

\section{REFERENCES}

Arun, G. 2017. The Gift of Anger; Penguin.

Desmond, T. and Douglas, A. 2016. His Holiness the Dalai Lama. The Book of Joy: Lasting Happiness in a Changing World; Avery.

Kahneman, D. and Tversky, A. 2004. Conflict resolution: A cognitive perspective. In E. Shafir (Ed.), Preference, belief, and similarity: Selected writings by Amos Tversky ( $p$. 729-746). Boston Review.

Runde, Craig, E. and Flanagan, Tim, A. 2010. Developing Your Conflict Competence; Center for Creative Leadership and Jossey-Bass.

Thupten, J. 2015. A Fearless Heart: How the Courage to be Compassionate can transform our lives; Avery. 
